\title{
Notas
}

\section{A abertura do Acervo Azeredo da Silveira da Fundação Getúlio Vargas}

\author{
MATIAS SPEKTOR
}

Mais uma vez, o Centro de Pesquisa e Documentação da Fundação Getúlio Vargas (CPDOC/FGV) traz ao público uma coleção de fontes primárias que promete elucidar alguns dos episódios mais fascinantes das relações internacionais do Brasil contemporâneo. A abertura, ainda que parcial ${ }^{1}$, do Acervo Embaixador Antônio Francisco Azeredo da Silveira (AAS), franqueia o acesso ao conjunto de idéias, percepções, opiniões, constrangimentos, amizades e desafetos que animaram os dias do diplomata responsável pela mais ampla revisão da política externa brasileira do pós-guerra.

Durante os cinco anos em que esteve à frente do Itamaraty (1974-1979), o chanceler do Presidente Geisel desengajou o Brasil de sua tradicional relação com três eixos centrais: Argentina,Estados Unidos e Portugal ${ }^{2}$. A nova postura da chancelaria face a esses países possibilitou a mundialização das relações exteriores do país mediante intensa e vasta agenda na América do Sul, na Europa Ocidental, no Oriente Médio, na Ásia e na África.

As escolhas de Silveira cindiram a opinião de seus contemporâneos. $\mathrm{Na}$ Esplanada dos Ministérios, a linha dura não hesitou em denunciar o independentismo da política externa do Ministro no intuito de radicalizar posições contra o projeto de liberalização política de $\mathrm{Geisel}^{3}$. No Itamaraty, as vozes contrárias às concepções do chanceler argumentavam que, ao turvar a amizade com Buenos Aires e Washington, Silveira estava condenando as relações internacionais do país a um sem fim de irreparáveis danos ${ }^{4}$.

Não faltaram pressões nas praças diplomáticas mais afetadas pela nova orientação diplomática do Brasil da década de 1970. Silveira conseguiu provocar uma significativa mobilização no establishment diplomático norte-americano. $\mathrm{O}$ seu fluido relacionamento pessoal com Kissinger, que resultara na criação de um inusitado sistema de consultas entre os dois governos e encontros informais entre os dois ministros, em nenhum momento negligenciou uma agenda bilateral crescentemente marcada por desencontros pontuais que punham fim ao padrão de inteligência que marcara as relações entre ambos países desde princípios do século XX. As divergências abarcavam a política africana do Brasil, as posturas divergentes 
em relação ao Suriname e ao Caribe, as pendências comerciais envolvendo a Embraer e a indústria de armamentos, e a malfadada renovação do sistema interamericano proposta pelo estadista norte-americano. Findo o governo Ford, as pressões da Casa Branca de Carter sobre o Brasil ganharam vulto - incluindo o envolvimento do Vice-Presidente Mondale, da Primeira-Dama, do Secretário de Estado Vance e do embaixador Crimmins - para dissuadir Geisel e Silveira da cooperação nuclear com a Alemanha mediante a articulação do incipiente regime internacional de proteção aos direitos humanos.

Ao sul, a Junta Militar portenha decidiu reagir à política brasileira de rios mediante a nomeação de um dos principais formuladores do espírito de colaboração consagrado pelos acordos de Uruguaiana (1961) para a embaixada em Brasília Oscar Camilión. Esperava-se, dessa forma, garantir uma saída honrosa para a Argentina. Camilión rapidamente garantiu a adesão dos meios de comunicação brasileiros à sua causa, qual fosse o reconhecimento, por parte do Itamaraty, de que Itaipu não era assunto de política doméstica e, portanto, devia ser negociado no quadro do direito internacional dos recursos hídricos compartilhados ${ }^{5}$.

Ao convidar Silveira para integrar-se ao ministério, Geisel confessou ter lido atenciosamente a correspondência dos principais embaixadores do quadro do Itamaraty. O General tinha a convicção de que era necessário enveredar pelo caminho das mudanças sugeridas por Silveira desde o seu posto na embaixada brasileira em Buenos Aires. Sabendo das resistências que o nome de Silveira geraria, Geisel teria afirmado a ele que "se atirarem pedras no seu telhado, eu estarei ao seu lado para defendê-lo". Além da simpatia pessoal que Geisel nutria por seu chanceler, seu gosto pessoal pela diplomacia é evidenciado pelo número de horas que o mandatário despachou com esse ministro, superando significativamente a média de encontros com os outros membros da equipe de governo ${ }^{6}$.

Silveira provocou as situações que acreditou serem viáveis para obter benefícios numa ordem internacional em transformação. A maleabilidade da estrutura internacional de poder no período era excepcional: o relacionamento entre as duas superpotências fracassou em manter o equilíbrio de forças construído desde 1960; a aliança atlântica entre europeus e norte-americanos perdeu o espírito de comunhão do pós-guerra e não resistiu às pressões autonomistas de uma Europa Ocidental economicamente fortalecida mas politicamente submetida ao ritmo de Washington; o fracasso dos Estados Unidos na Ásia mostrou ao mundo os limites domésticos e internacionais da potência hegemônica; na vizinhança sul-americana, a Argentina apostou no caminho do isolamento internacional; no Atlântico, a África portuguesa declarou a sua independência etc.

Contudo, a organização do novo mapa diplomático brasileiro não pôde elevar o seu potencial: a política externa brasileira sucumbia aos efeitos devastadores da crise das dívidas externas latino-americanas, ao recrudescimento da política norte- 
americana para o império soviético e ao fim gradual, mas certeiro, do modelo de desenvolvimento nacional ${ }^{7}$.

Para os estudiosos de assuntos internacionais, a riqueza do Acervo Azeredo da Silveira é complementada pela recente abertura do Acervo Ernesto Geisel (também da FGV). Sem dúvida, o material disponível facilitará a avaliação e desenvolvimento da literatura especializada sobre o período, que já conta uma produção acadêmica significativa ${ }^{8}$.

O Acervo Silveira oferece uma visão panorâmica da natureza e do escopo das pressões que um país como o Brasil atravessou e provocou na sua história recente. Por ter sido um período de redefinições políticas globais de fundo, essa documentação revela de que forma o país assistiu ao entrelaçamento do velho e do novo na definição da ordem mundial contemporânea.

Os documentos também constituem uma contribuição para a reflexão acerca dos benefícios que uma chancelaria oferece à sua sociedade. A recuperação dos eventos, assim como do quadro mental que guiou o Chanceler, o Presidente e seus interlocutores nacionais e internacionais, oferece pistas inovadoras para a resolução desse interrogante. O material também é excelente fonte de insumos para a análise de mentalidades no campo da política externa brasileira, seara de estudos bastante promissora, porém inexplorada.

Finalmente, esta é mais uma oportunidade para trazer à agenda contemporânea alguns dos temas mais candentes da vida internacional brasileira nos primeiros anos do século XXI. Os desafios internacionais de hoje não deixam de tomar novas formas e matizes quando contrapostos aos limites, possibilidades e escolhas de ontem.

\section{Notas}

1 Em meados de Abril de 2001, a Fundação Getúlio Vargas havia aberto para consulta todas as seções já organizadas do Acervo, que incluem quase 21 horas de depoimentos do Embaixador Azeredo da Silveira, a sua coleção particular de correpondências oficiais do período em que chefiou a Embaixada brasileira em Buenos Aires (1969-1974) e os volumes completos das Informações ao Senhor Presidente da República (1974-1979). Resta a organização e abertura da correspondência e objetos pessoais do Embaixador, as pastas referentes aos seus anos à frente das embaixadas em Washington (1980-1982) e Lisboa (1982-1985) e uma coleção de aproximadamente 6.000 fotografias. Espera-se que o Acervo seja inteiramente aberto ao público até finais de 2001.

2 Este triângulo ocupou os últimos anos da carreira de Silveira, que chefiou as embaixadas em Buenos Aires (1969-1974), Washington (1979-1982) e Lisboa (1982-1985).

3 Um dia após ser exonerado do Ministério do Exército, o general Sílvio Frota acusava o Presidente de ter-se rendido ao marxismo internacional ao promover a abertura para a China comunista.

4 As apaixonadas críticas de Roberto Campos à política externa de Geisel encontram-se em diversos trechos de suas mémórias, Lanterna na Popa, Topbooks, 1994. Para um exemplo mais recente desse argumento, ver o seu Prefácio em Moniz Bandeira, Relações Brasil-EUA no 
contexto da globalização, $2^{\circ}$ volume, $2^{\mathrm{a}}$ edição, revista e ampliada, Senac: Sao Paulo, 1999.

Ver Oscar Camilión, Memórias políticas: de Frondizi a Menem (1956-1996). Planeta: Buenos Aires, 1999.

6 Geisel dedicou, aproximadamente, 230 horas de despacho à política externa ao longo de seu mandato. A segunda pasta colocada foi a da Justiça, com 186 horas de encontro entre o Presidente e o ministro responsável. Ver Armando Falcão, Geisel, do Tentente ao Presidente. Rio de Janeiro: Nova Fronteira, 1995.

7 Para uma interpretação da política externa de Geisel na vertente internacional do projeto nacionaldesenvolvimentista, ver Paulo Fagundes Vizentini, A politica externa do regime militar brasileiro, Porto Alegre: UFRGS, 1998.

8 Gino Costa, Brazil's foreign policy towards her neighbours during the Geisel years. PhD Thesis, University of London, 1986; Luiz F. L. Ferreira, A Politica Externa Latino Americana do Governo Geisel. Dissertação de Mestrado, Pontifícia Universidade Católica do Rio de Janeiro, 1993; Antônio Carlos Lessa. Brasil, EUA e Europa Ocidental no Contexto do Nacional Desenvolvimentismo: Estratégias de Diversificação de Parcerias (1974-1979). Dissertação de Mestrado, Universidade de Brasília, 1994; Luiz Fernando Ligiero, Políticas Semelhantes em Momentos Diferentes: exame e comparação entre a Política Externa Independente (1961-1964) e o Pragmatismo Responsável (1974-1979). Tese de Doutoramento, Universidade de Brasília, 2000; Maria Regina Soares de Lima. The political economy of brazilian foreign policy: nuclear policy, trade and Itaipu. $\mathrm{PhD}$ Thesis, Vanderbilt University, 1986; Leonel Itaussu Mello. Brasil, Argentina e a balança de poder regional: equilíbrio, preponderância ou hegemonia? (19691986). Tese de Doutoramento, Universidade de São Paulo, 1991; Letícia Pinheiro. Foreign policy decision-making under the Geisel government: the President, the military and the foreign ministry. PhD Thesis, London School of Economics and Political Science, 1994. 